\title{
The Influence of Terms of Pulp Extirpation during Tooth Auto Transplantation on Resorption and Ankylosis in Adults
}

\author{
Kristina Badalyan ${ }^{1}$, Alena Zedgenidze ${ }^{1^{*}}$ \\ ${ }^{1}$ Department of Clinical and Experimental Implantology of National Medical Research Center of Dentistry and \\ other Facial Surgery, Saint Timura Frunze, 16, Moscow, Russia \\ *Corresponding Author: Alena Zedgenidze, Department of Clinical and Experimental Implantology of \\ National Medical Research Center of Dentistry and other Facial Surgery, Saint Timura Frunze, 16, Moscow, \\ Russia; Email: endotreat@gmail.com
}

Received Date: 02-09-2020; Accepted Date: 01-10-2020; Published Date: 09-10-2020

Copyright $^{\oplus} 2020$ by Badalyan K, et al. All rights reserved. This is an open access article distributed under the terms of the Creative Commons Attribution License, which permits unrestricted use, distribution, and reproduction in any medium, provided the original author and source are credited.

\begin{abstract}
Objectives: According to the studies, the best time for endodontic treatment after accidental replan-tation is no more than two weeks. Unlike cases of tooth trauma, in autotransplantation, all the manipulations flow under relatively sterile conditions and the likelihood of pulp infection is minimal. We decided to check out the resorption rate in case of different terms of pulp extirpation and whether revascularization is possible with a favorable healing course.
\end{abstract}

Material and Methods: In this study we performed the autologous transplantation of closedapex third molars in 52 adult patients, divided in 3 groups. In the $1^{\text {st }}$ group ( 8 cases) the pulp extirpation was done before the surgery, in the $2^{\text {nd }}$ group it was performed in 2 weeks after the surgery $(33$ cases $)$. In the $3^{\text {rd }}$ group there was no treatment at all $(11$ cases $)$.

Results: Results were evaluated after 3, 6, 12, 24 months by clinical and radio-graphic examination. The survival rate and the pulp condition of the transplanted teeth was observed. The dynamic periotestometry examination was performed in order to track the resorptive processes. For statistical data processing we used the Mann-Whitney test.

Conclusions. No dependence of the development of inflammatory and replacement resorption on the time of pulp extirpation was evaluated. During this observation period direct confirmation of revascularization has not been obtained. Despite possible pulp necrosis inside the transplanted tooth, the risk of inflammatory resorption is minimal in the absence of

Badalyan K | Volume 1; Issue 2 (2020) | JDHOR-1(2)-012 | Research Article

Citation: Badalyan K, et al. The Influence of Terms of Pulp Extirpation during Tooth Auto

Transplantation on Resorption and Ankylosis in Adults. J Dental Health Oral Res. 2020;1(2):1-12. 
infection. Periotestometry data showed that process of replacement resorption stopped after 6 months in most cases.

\section{Keywords}

Autologous Transplantation; Resorption; Ankylosis; Pulp Extirpation; Revascularization; Periotestometry

\section{Introduction}

In accidental replantation, the recommended time for endodontic treatment is no more than two weeks [1]. It is explained by the pulp infection and the damage of the root surface which initiates the inflammatory resorption process. On contrary, in auto transplantation the tooth most likely remains uninfected, which requires a review of the timing and need of endodontic treatment in general. Root inflammatory resorption is a progressive process of dentin resorption that occurs in a transplanted or replanted tooth with a damaged periodontal ligament and infected pulp [1-3].

Bacteria and their metabolic products migrate along the tubules to the root surface, causing an inflammatory response in the surrounding tissues [4]. It occurs when the osteoclasts penetrate the cement layer and comes into contact with the dentinal tubules, which are associated with infected tissue of a necrotic pulp. However, if the resorption cavity does not penetrate into the intermediate cement layer, a tooth with necrotic pulp will cause only surface resorption, and the intermediate cement layer will inhibit the spread of toxic elements [5]. If the inflammatory resorption occurs the main characteristic of its presence is granulation tissue, which contains a large number of vessels in the resorptive lacunae, which makes this zone radiopaque, so we can observe it on X-ray pictures within 1 and 2 months after transplantation [5-9]. In rare cases, delayed inflammatory resorption can be also observed in the cervical part of the root in several years after transplantation [10,11]. On the other hand, some studies reported a complete absence of inflammatory resorption [12-15]. The absence of complications could be provided by careful transplant manipulation and sterile pulp chamber. According to the literature, endodontic treatment is extremely important for the success of tooth auto transplantation with closed apex. However, the recommended pulp extirpation time re-mains controversial. Recommendations on the terms of endodontic treatment vary in different sources from 7 to 14 days [16-18]. In some studies, endodontic treatment was delayed or was not performed at all, especially in young patients with transient step of apical third development, when the root is fully formed, but the apical foramen is still wide [19]. According to some authors such teeth do not need pulp extirpation due to the chance of revascularisation [20,21]. 


\section{Material and Methods}

In this study, third molars were transplanted in adults aged 18 to 76 years. We used recommended auto transplantation protocol: atraumatic extirpation, extra-oral time no more than 15 minutes in wet environment, 3D model usage if needed, non-rigid splinting for 4 weeks in average [2]. Firstly, the groups were divided by the root anatomy on the group with fully closed apexes and the group with $1 \mathrm{~mm}$ in diameter apexes. Donors with wide apexes were transplanted without any treatment - (group 1: 11 cases). The transplants had one root and, radiologically, the apical distance between the walls of the root in apical third was at least 1 $\mathrm{mm}$ (Fig. 1). Thus, in the remaining cases the necessary endodontic treatment was performed before surgery (group 2: 8 cases) and within 2 weeks after the transplantation (group 3: 33 cases). This division was due to the possibility of secure rubberdam placing because in most of the cases donor tooth was not fully erupted. That is why the root canal management was done after the surgery and the rubberdam clasp was positioned on a distal tooth to minimise periodontal trauma (Fig. 2). Endodontic treatment included mechanical root canal enlargement up to size 35/02 profile (Dentsply), irrigation with sodium hypochlorite solution 3\% (Par-can 3\%, Septodont) and EDTA 17\% (MD cleanser Meta biomed), vertical gutta-percha filling with sealer AH plus (Dentsply). During the treatment, control radiographs were performed. All trans-planted teeth were introduced into occlusion during the first 6 months after transplantation by prosthetics or direct resin restoration. Results were obtained after 3, 6, 12, 24 months. During the clinical examination we evaluated the colour of the crown, cold test, percussion, the depth of periodontal attachment measured at 6 points. At the X-ray examination the width of the periodontal ligament space and signs of inflammation were estimated by two specialists. For teeth that have not under-gone endodontic treatment a cold test was applied.

For this study, we used the Periotest device, which consists of a shock and measuring device. The tip transmits an electronically controlled mechanical impulse to the tooth; the control coil provides a constant frequency of impulses of the striker with compensation for friction and gravity. Periotest measurements can vary from -8 to +50 . Values from -8 to +9 are considered normal, from +10 to +19 correspond to first distinguishable sign of movement, from +20 to +29 to mobility, de-termined visually when crown deviates within $1 \mathrm{~mm}$ of its normal position, from +30 to +50 to easily noticeable mobility [22]. Using the periotestometry data we analysed tooth mobility changes during 2 years (Fig. 3). Periotestometry was performed by two specialists in a horizontal position of the patient. Mann-Whitney test was used for statistical data processing. 

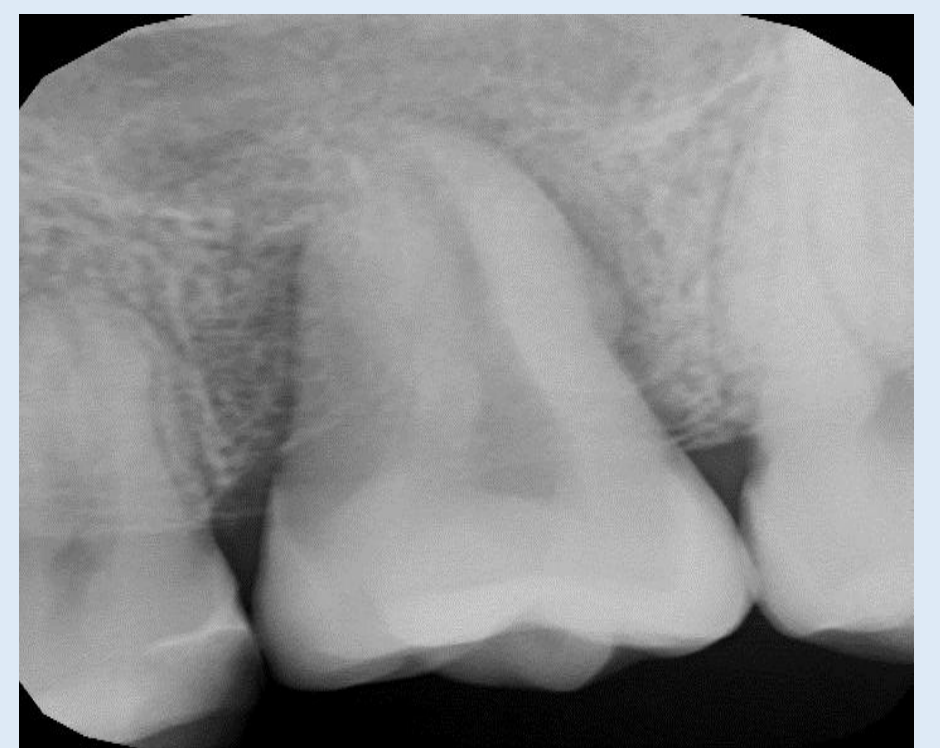

Figure 1: Example of wide apex donor tooth from $1^{\text {st }}$ group.

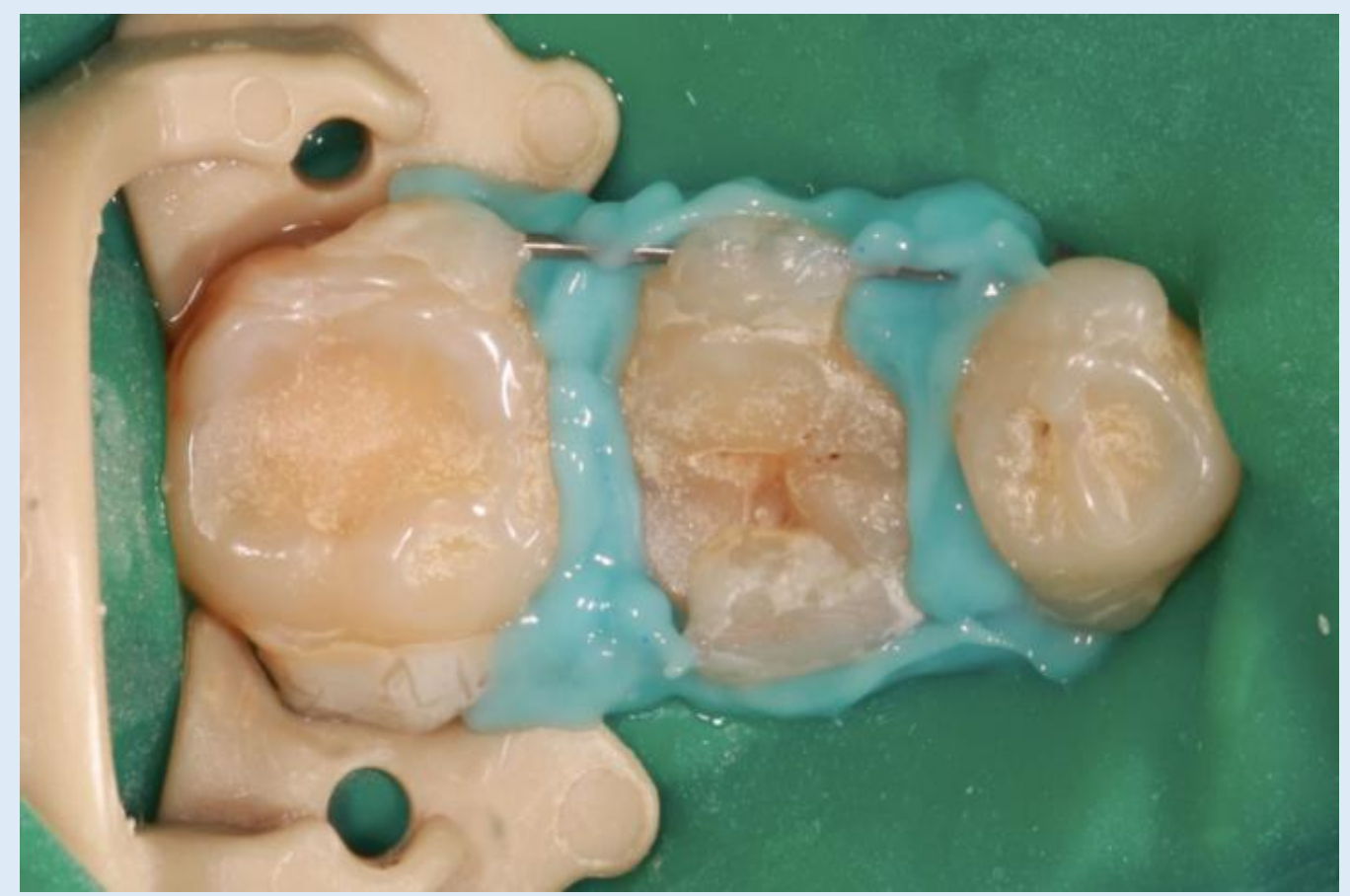

Figure 2: Example of rubberdam placing to minimise the trauma of periodontal ligament of transplant. 


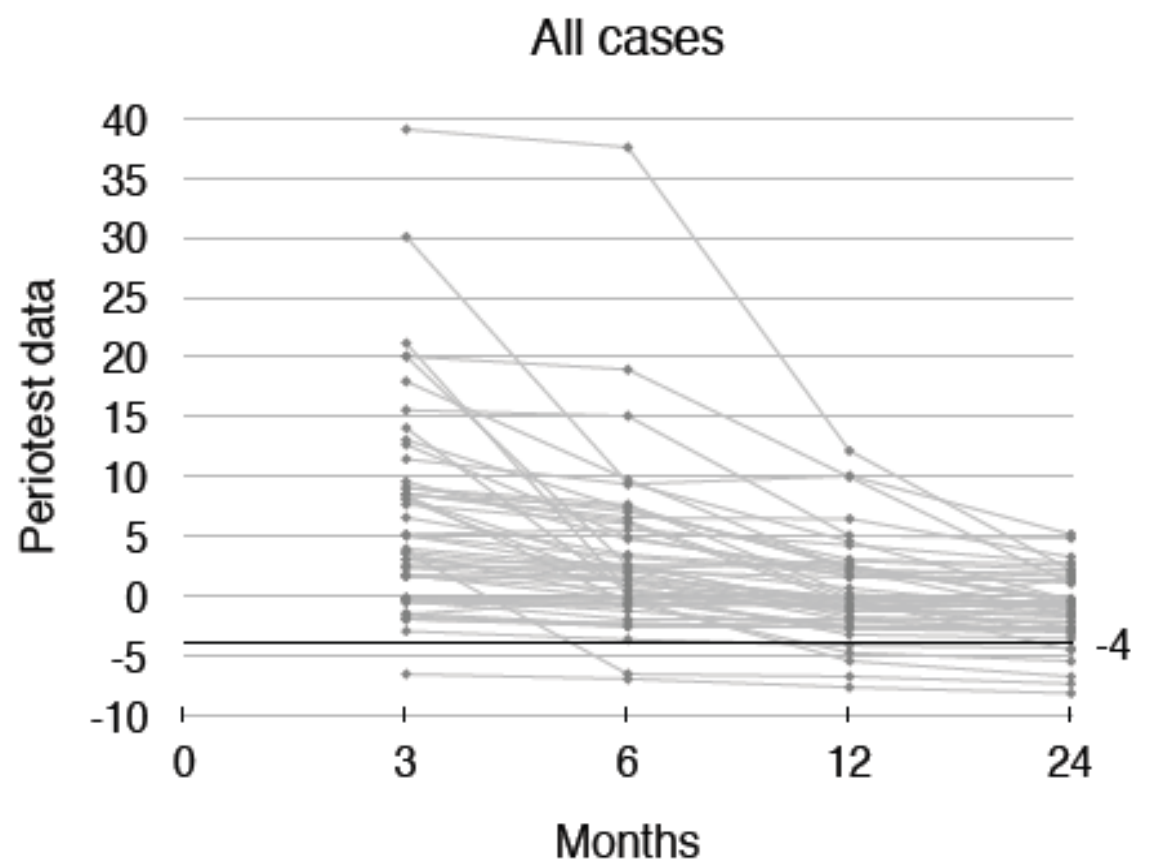

Figure 3: Periotest data for all cases. Values under -4 (cu) are considered as ankylotic.

\section{Results}

In all cases of the absence of endodontic treatment (group 1) during clinical examination, signs of inflammatory resorption were not detected. The teeth also had not changed the colour. The depth of periodontal attachment was not more than $3 \mathrm{~mm}$. The result of cold test in all cases was negative. While analysing $\mathrm{x}$-rays, signs of periapical inflammation were detected in 2 cases, endodontic treatment was done afterwards (Fig. 4-7). In 5 cases, the periodontal ligament space was narrowed or could not be seen. The periotestometry values showed drastic changes in first 6 months, however, subsequently, teeth were stable in 9 cases, during the 2 year period. Final measurements after 2 years showed normal mobility [-4, 5, $5 \mathrm{cu}$ Periotest $]$ in all cases (100\%) (Fig. 8).

In group where endodontic treatment was carried out before the surgery (group 2), clinical signs of inflammation also were not detected. In 2 cases there was a local damage of periodontal attachment leading to recessions of $3 \mathrm{~mm}$. Periotestometry data showed sharp decrease in values in first 6 months in 3 cases. No tooth mobility was detected after 2 years, the values of periotestometry were distributed as normal in 7 cases, ankylosis was detected in 1 case (Fig. 9). The X-rays showed narrowing of the periodontal gap in certain areas in 3 cases.

In the $3^{\text {rd }}$ group root canal treatment was done in 2 weeks after the surgery and clinically showed no signs of inflammation. In 4 cases a partial loss of periodontal attachment on the distal surface was observed. The depth of the recessions was $5 \mathrm{~mm}$ ( 3 cases) and $7 \mathrm{~mm}$ ( 1 case). 
In addition, this transplants had excessive mobility 3 months after surgery, but no mobility was observed after two years (Fig. 10). In 17 cases areas of narrowing of the periodontal ligament space were determined on the radiograph. Periotestometry values obtained 2 years after surgery in 30 cases revealed normal mobility; 3 cases were determined ankylotic.

Statistical data processing was performed using the Mann-Whitney test for multivariate analysis of unrelated groups. It was shown that at a significance level of 0.05 we cannot reject the null hypothesis that the values of the periotest are distributed identically in teeth with pulp extirpated and teeth without endodontic treatment (p-value $=0.43)($ Fig. 11,12) $[23,24]$.

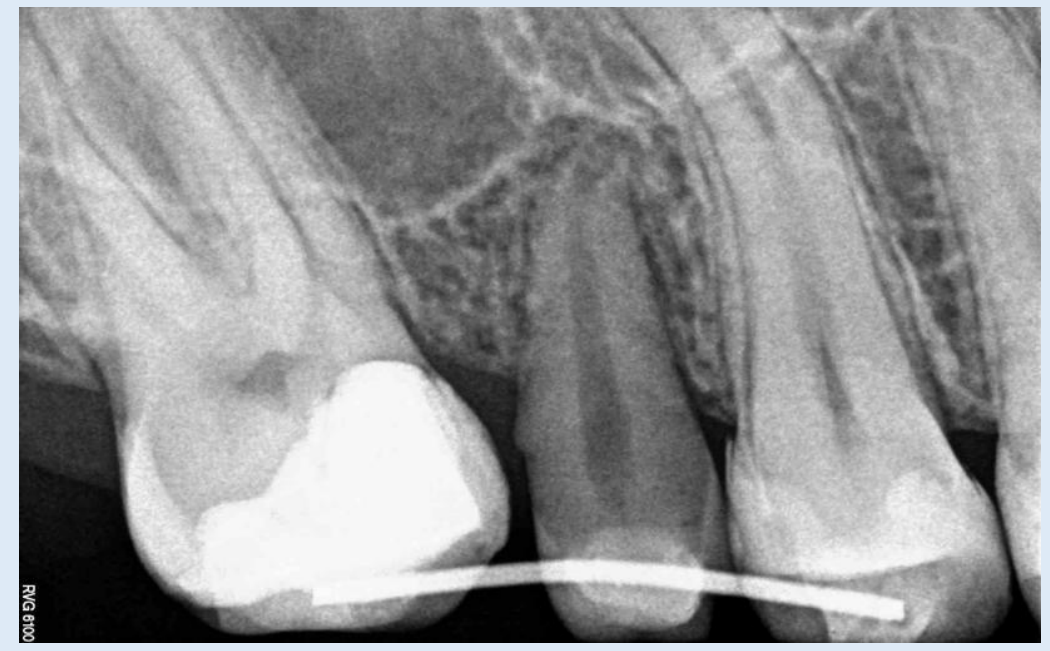

Figure 4: Wide apex transplant 4 weeks after the surgery with confirmed apical periodontitis.

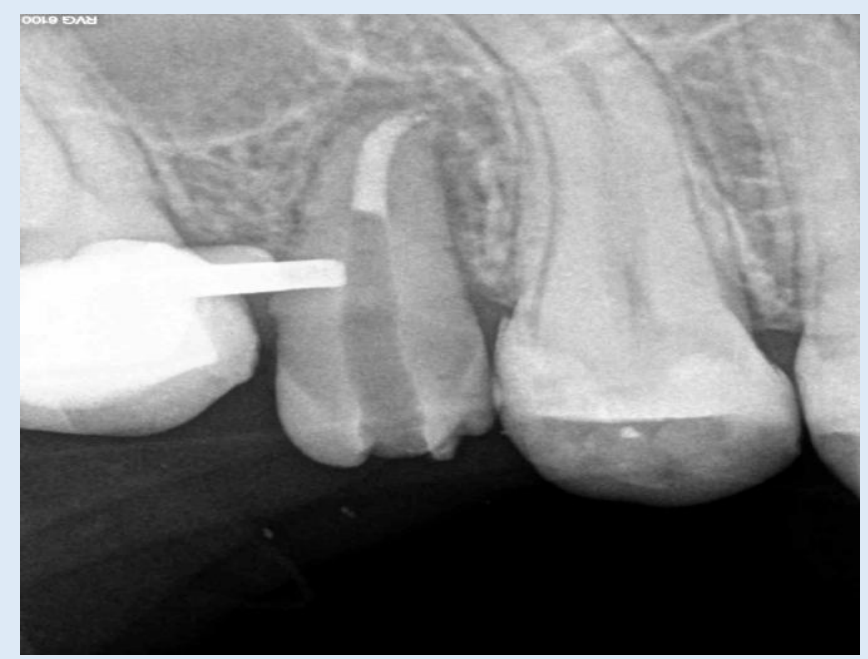

Figure 5: Endodontic treatment. Apical plug control. 


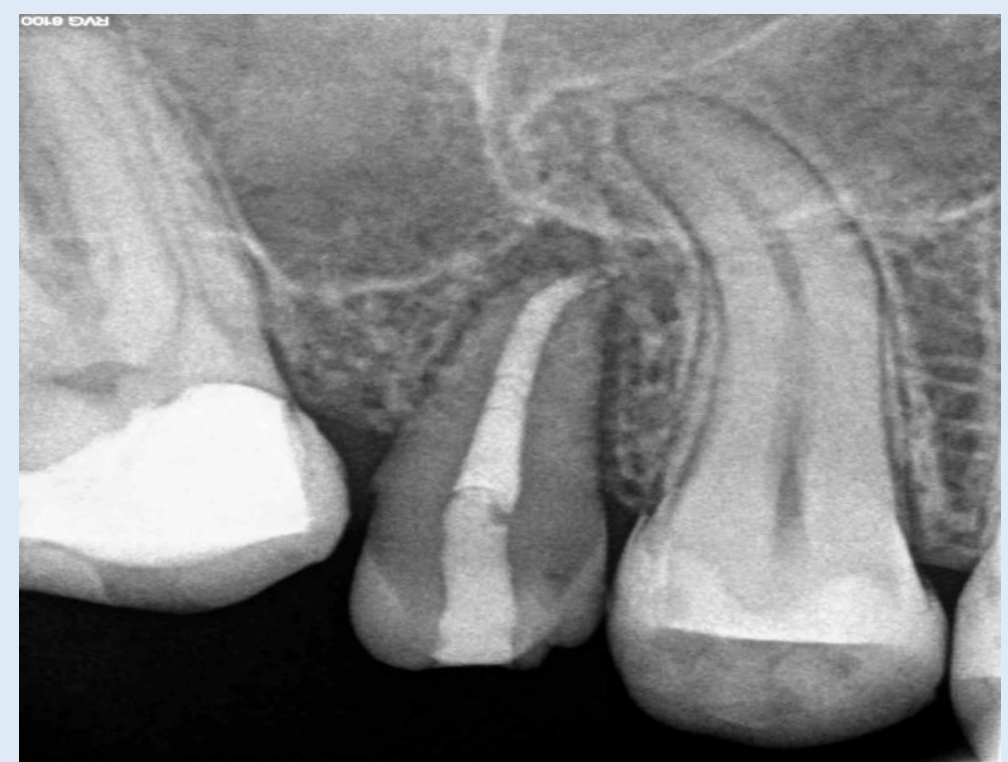

Figure 6: 3 months after transplantation.

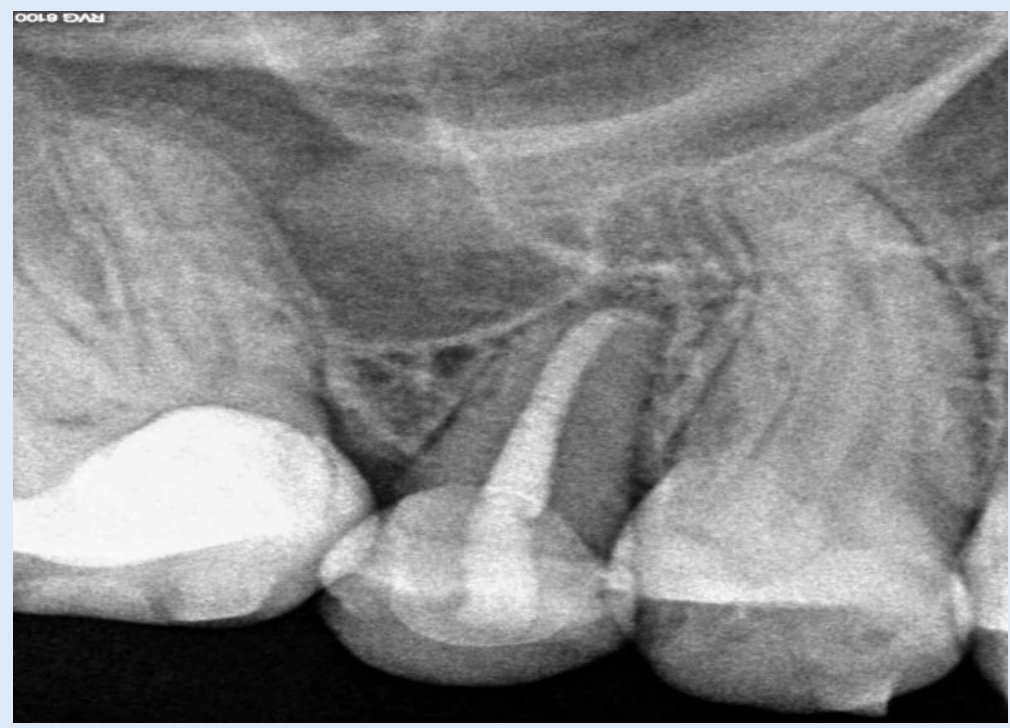

Figure 7: 1 year after transplantation.

Badalyan K | Volume 1; Issue 2 (2020) | JDHOR-1(2)-012 | Research Article

Citation: Badalyan K, et al. The Influence of Terms of Pulp Extirpation during Tooth Auto Transplantation on Resorption and Ankylosis in Adults. J Dental Health Oral Res. 2020;1(2):1-12. 


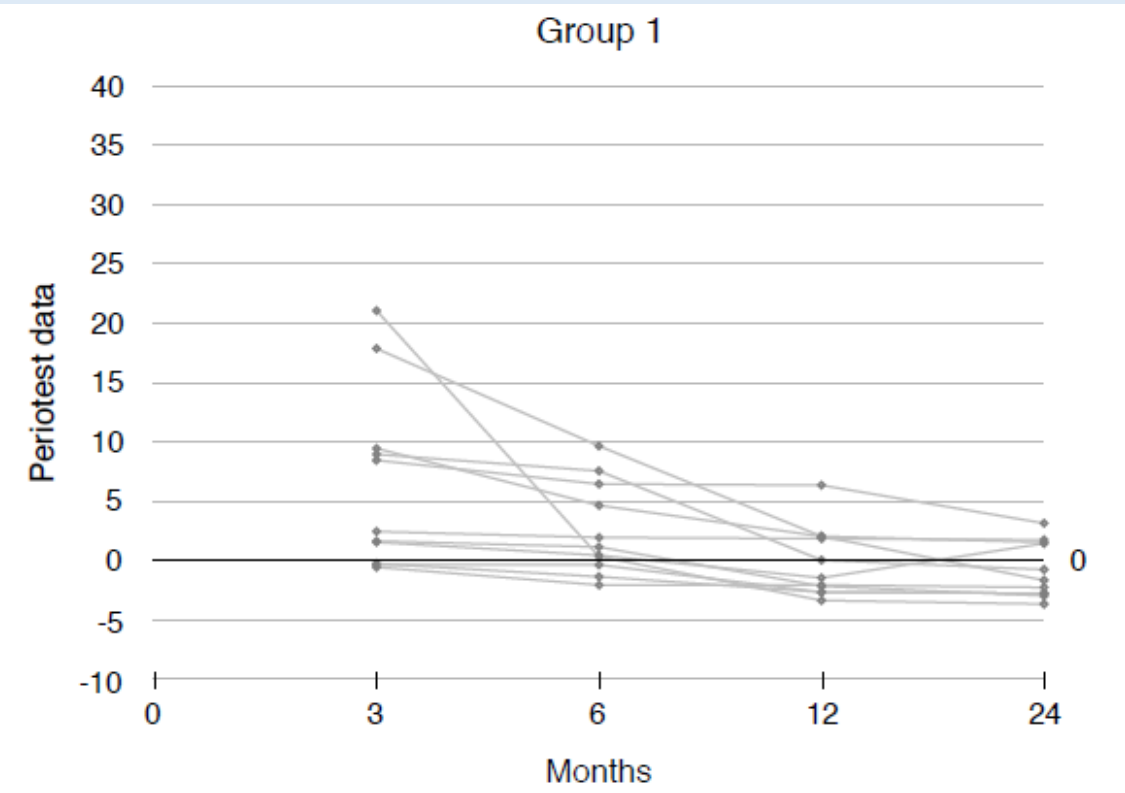

Figure 8: Periotest data for teeth with leaved pulp.

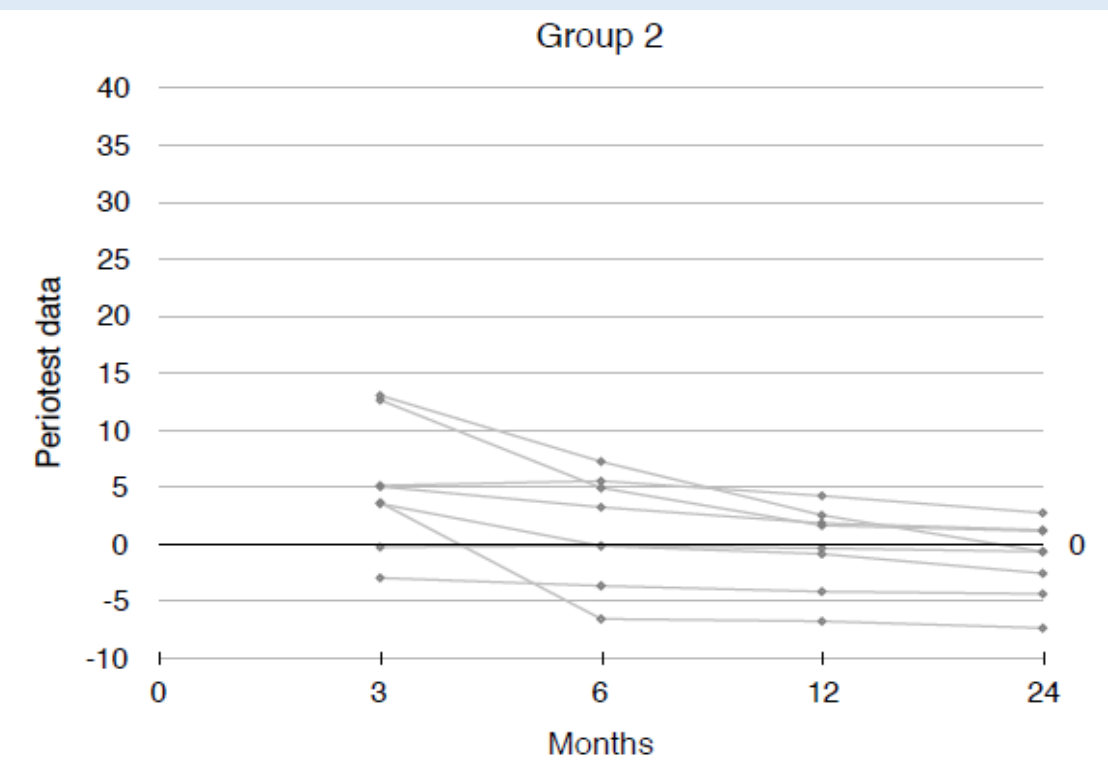

Figure 9: Periotest data for teeth underwent pulp extirpation before the surgery. 


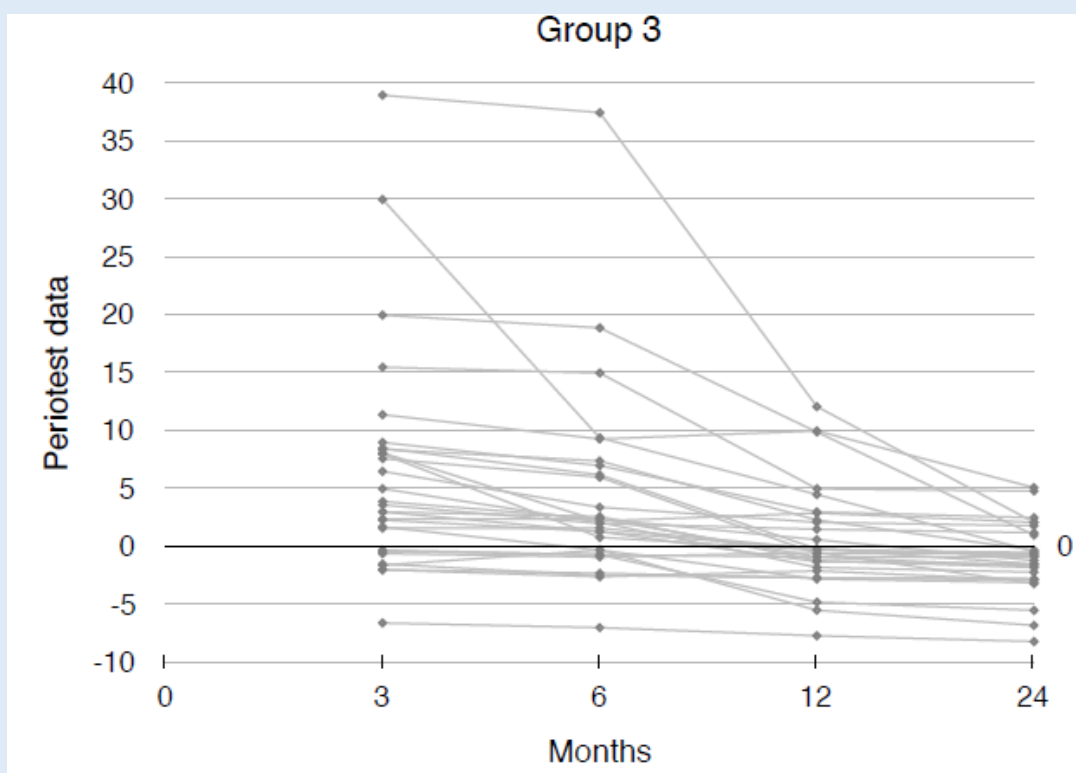

Figure 10: Periotest data for teeth underwent pulp extirpation in 2 weeks after the surgery.

\begin{tabular}{|c|c|c|c|c|c|c|c|}
\hline & $\begin{array}{r}\text { Inflammato } \\
\text { ry } \\
\text { resorption }\end{array}$ & Periodontitis & $\begin{array}{r}\text { Attachment } \\
\text { loss }\end{array}$ & $\begin{array}{l}\text { No PDL } \\
\text { on x-ray }\end{array}$ & $\begin{array}{r}\text { Increased } \\
\text { mob }(>5,5 \mathrm{cu} \\
\text { periotest })\end{array}$ & $\begin{array}{r}\text { Normal } \\
\text { mobility }(-4 ; \\
5,5 \mathrm{cu} \\
\text { periotest) }\end{array}$ & $\begin{array}{r}\text { Ankylosis } \\
(<-4 \mathrm{cu} \\
\text { periotest })\end{array}$ \\
\hline $\begin{array}{l}\text { Group } 1 \\
\text { (11) } \\
\text { no endo }\end{array}$ & 0 & 2 & 0 & 5 & 0 & 11 & 0 \\
\hline $\begin{array}{l}\text { Group } 2 \\
\text { (8) } \\
\text { preop } \\
\text { endo }\end{array}$ & 0 & 0 & 2 & 3 & 0 & 7 & 1 \\
\hline $\begin{array}{l}\text { Group } 3 \\
\text { (33) } \\
\text { postop } \\
\text { endo }\end{array}$ & 0 & 0 & 4 & 17 & 0 & 30 & 3 \\
\hline
\end{tabular}

Figure 11: Case distribution according to the following parameters. 


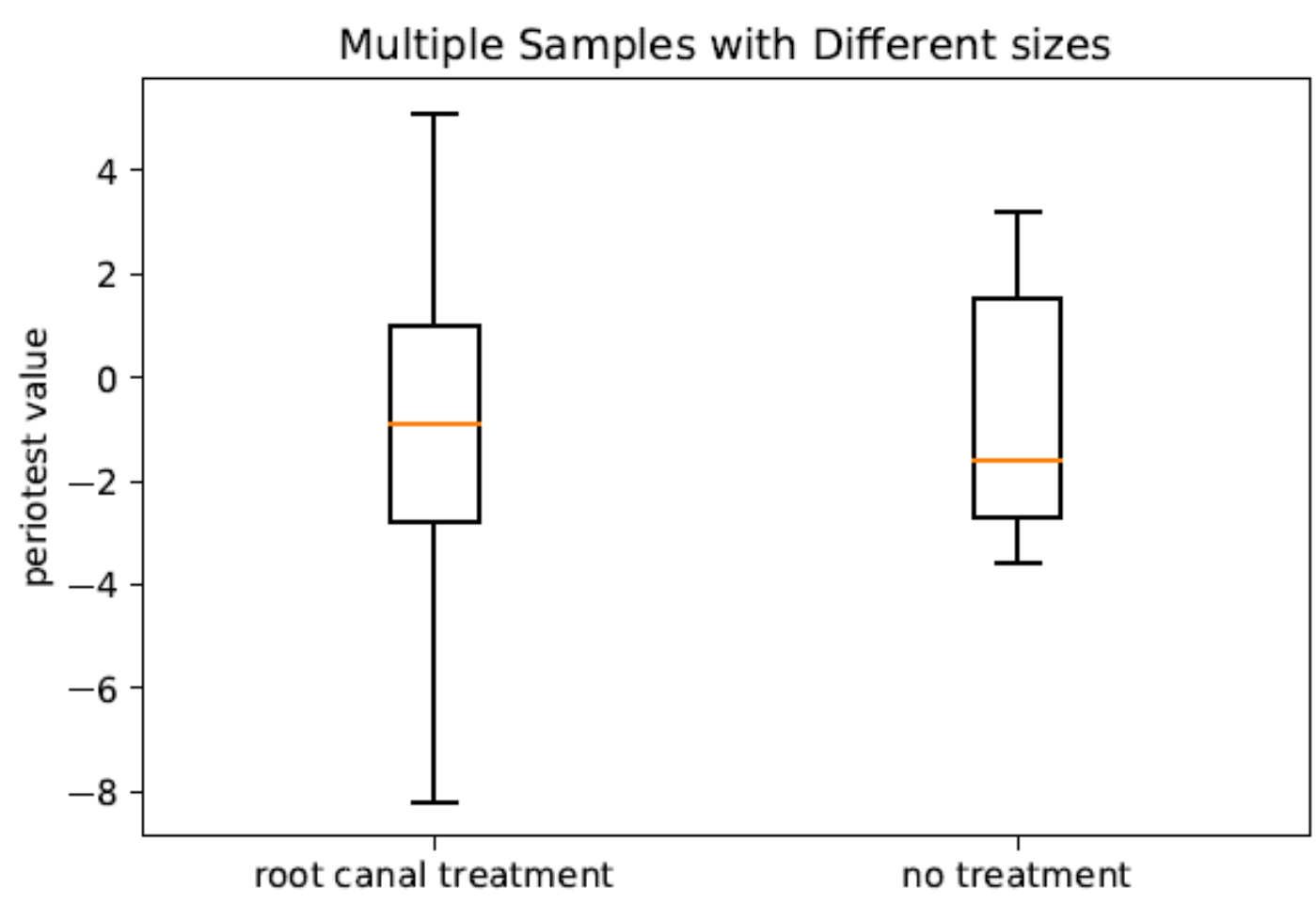

Figure 12: Distribution of periotestometry values for pulp extirpated and not-extirpated teeth 2 years after autotransplantation.

\section{Conclusion}

According to the results of the study no dependence of the development of inflammatory and re-placement resorption on terms of pulp extirpation was evaluated. The results obtained in the 1 group, where pulp extirpation was not performed, did not show the presence of an inflammatory process in the periodontium. The absence of attachment loss in this group is apparently caused by the full root coverage by the periodontal ligament and good condition of recipient zone. Despite the negative cold tests and possible pulp necrosis inside the transplanted tooth, the risk of inflammatory resorption is minimal in the absence of infection. During the observation period of 2 years direct confirmation of revascularization has not been obtained, however these patients will be examined further. Probably it makes sense to use pulse oximetry test to determine blood flow in the pulp chamber. Periotestometry data showed that process of replacement resorption stopped after 6 months in most cases.

In groups, where endodontic treatment was performed, the risks associated with infection of the pulp chamber and the periodontal ligament injury during the treatment were minimized. Even so, ankylosis occurred in $97 \%$ cases probably due to the trauma of root cement during 
auto transplantation. However, periotestometry values after six months remained stable, which indicates a suspended resorption process. The recession's occurred on distal surfaces most likely caused by the lack cortical recipient bone volume, which led to the attachment formation at the level of existing bone tissue.

We received satisfactory results of auto transplantation during this study. Stable result within 2 years after the operation makes it possible to use this operation on daily basis. The study showed that in adult patients there is no need for immediate pulp extirpation under the condition of wide apex. Perhaps, in auto transplantation there is a chance of blood supply restoration when the absence of pulp infection provided. In this case, the indication for endodontic treatment will be symptoms of apical periodontitis or the presence of inflammatory resorption. Both of these conditions need to be regularly monitored.

According to the literature, the restoration of pulp sensitivity after an injury can occur within several years. Moreover, blood supply can be restored much earlier, which was determined by some researchers using pulse oximetry. Due to the use of molars for transplantation, this the research method was not available due to the anatomical structure of the coronal part. Nevertheless, this region is of great interest and requires further observations.

\section{Acknowledgments}

Great and special gratitude to I Khisambeev, statistical analysis expert.

\section{References}

1. Andreasen JO. Relationship between surface and inflammatory resorption and changes in the pulp after replantation of permanent incisors in monkeys. J Endod. 1981;7(7):294-301.

2. Tsukiboshi M. Autotransplantation of teeth: requirements for predictable success. Dent Traumatol. 2002;18(4):157-80.

3. Andreasen JO. 1981 The effect of pulp extirpation or root canal treatment on periodontal healing after replantation of permanent incisors in monkeys. J Endod. 1981;7:245-52.

4. Andreasen JO, Hjørting-Hansen E. Replantation of teeth. I Radiographic and clinical study of 110 human teeth replanted after accidental loss. Acta Odontol Scand. 1966;24:263-86.

5. Andreasen JO, Hjørting-Hansen E. Replantation of teeth. II Histological study of 22 replanted anterior teeth in humans. Acta Odontol Scand. 1966;24:287-306.

6. Andreasen JO, Paulsen HU, Yu Z, Ahlquist R, Bayer T, Schwartz O. A long term study of 370 autotransplanted premolars. Part I- surgical procedure and standardized techniques for monitoring healing. Eur J Orthod. 1990;12:3-13.

7. Andreasen JO, Paulsen HU, Yu Z, Bayer T, Schwartz O. A long term study of 370 autotransplanted premolars. Part II- tooth survival and pulp healing subsequent to transplantation. Eur J Orthod. 1990;12:1424.

8. Andreasen JO, Paulsen HU, Yu Z, Schwartz O. A long term study of 370 autotransplanted premolars. Part III- periodontal healing subsequent to transplantation. Eur J Orthod. 1990;12:25-37.

Badalyan K | Volume 1; Issue 2 (2020) | JDHOR-1(2)-012 | Research Article 
9. Andreasen JO, Paulsen HU, Yu Z, Bayer T. A long term study of 370 autotransplanted premolars. Part IV. Root development subsequent to transplantation. Eur J Orthod. 1990;12:38-50.

10. Andreasen J. Atlas of replantation and transplantation of teeth. Surg Anatomy Wound Healing. 1992;1556.

11. Schatz JP, Joho JP. A clinical and radiologic study of autotransplanted impacted canines. Int J Oral Maxillofac Surg. 1993;22(6):342-6.

12. Gault PC1, Warocquier-Clerout R Wang. Tooth auto-transplantation with double periodontal ligament stimulation to replace periodontally compromised teeth. J Periodontol. 2002;73(5):575-83.

13. Sugai T, Yoshizawa M, Kobayashi T, Ono K, Takagi R, Kitamura N, et al. Clinical study on prognostic factors for autotransplantation of teeth with complete root formation. Int $\mathrm{J}$ Oral Maxillofac Surg. 2010;39(12):1193-203.

14. Flores MT, Andreasen JO, Bakland LK, Feiglin B, Gutmann JL, Oikarinen K, et al. Guidelines for the evaluation and management of traumatic dental injuries. Dent Traumatol. 2001;17(2):49-52.

15. Malmgren B, Andreasen JO, Flores MT, Robertson A, DiAngelis AJ, Andersson L, et al. International Association of Dental Traumatology guidelines for the management of traumatic dental injuries: 3 Injuries in the primary dentition. Dent Traumatol. 2012;28(3):174-82.

16. Hinckfuss SE, Messer LB. An evidence-based assessment of the clinical guidelines for replanted avulsed teeth. Part I: timing of pulp extirpation. Dent Traumatol. 2009;25(1):32-42.

17. Gonnissen H, Politis C, Schepers S, Lambrichts I, Vrielinck L, Sun Y, et al. Long-term success and survival rates of autogenously transplanted canines. Oral Surg Oral Med Oral Pathol Oral Radiol Endod. 2010;110(5):570-8.

18. Kokai S, Kanno Z, Koike S, Uesugi S, Takahashi Y, Ono T, et al. Retrospective study of 100 autotransplanted teeth with complete root formation and subsequent orthodontic treatment. Am J Orthod Dentofacial Orthop. 2015;148(6):982-9.

19. Moorrees CFA, Fanning EA, Hunt EE Jr. Age variation of formation stages for 10 permanent teeth. J Dent Res. 1963;42:1490-502.

20. Caldeira CL, Barletta FB, Ilha MC, Abrão CV, Gavini G. Pulse oximetry: a useful test for evaluating pulp vitality in traumatized teeth. Dental Traumatology. 2016;32(5):385-9.

21. Andreasen JO, Ahrensburg SS, Tendal B. Inappropriate use of meta-analysis in an evidence-based assessment of the clinical guidelines for replanted avulsed teeth. Timing of pulp extirpation, splinting periods and prescription of systemic antibiotics. Dent Traumatol. 2009;25(1):32-42.

22. W Schulte, B D'Hoedt, D Lukas, M Maunz, M. Steppeler. Periotest for measuring periodontal characteristics-Correlation with periodontal bone loss. J Periodontal Res. 1992;27(3):184-90.

23. Stewart C1.Timing of pulp extirpation for replanted avulsed teeth. Evid Based Dent. 2009;10(3):72.

24. Ritwik P1. Pulp extirpation within 14 days after tooth replantation reduces inflammatory root resorption. J Am Dent Assoc. 2012;143(5):496-7. 